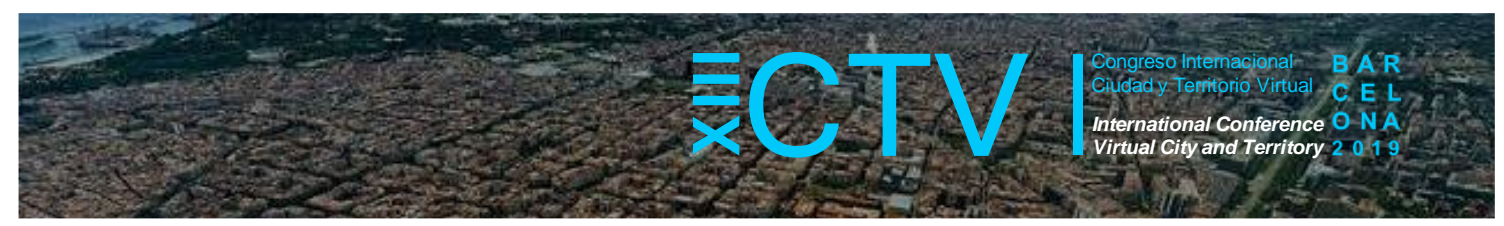

\title{
PRODUCCIÓN DE VIVIENDA INCLUSIVA A TRAVÉS DE PROCESOS DE RENOVACIÓN URBANA: EL CASO DEL PLAN PARCIAL TRIÁNGULO DE FENICIA EN BOGOTÁ - COLOMBIA
}

\author{
Pinilla, Juan Felipe ${ }^{1 *}$
}

Remisión inicial: 2019-06-30; Remisión definitiva: 2019-10-20; Publicación: 2019-12-21

Citación: Pinilla, J. F. (2019). Producción de vivienda inclusiva a través de procesos de Renovación Urbana: el caso del Plan Parcial Triángulo de Fenicia en Bogotá - Colombia. En XIII CTV 2019 Proceedings: XIII International Conference on Virtual City and Territory: "Challenges and paradigms of the contemporary city": UPC, Barcelona, October 2-4,2019. Barcelona:CPSV, 2019, p.8730. E-ISSN2604-6512.DOI http://dx.doi.org/10.5821/ctv.8730

\section{Resumen}

El objetivo principal de este trabajo es exponer un caso que ofrece evidencias sobre las potencialidades del reajuste de terrenos como "tercera vía" para la gestión de la tierra y la oferta de vivienda social en proyectos de renovación urbana. El caso es un proyecto ubicado en el centro de Bogotá, promovido por la Universidad de los Andes. Aunque está en su primera fase de ejecución, el proceso abierto y participativo de su formulación y las innovaciones en su propuesta de vinculación de actores lo han convertido en un referente en la ciudad. El proyecto tiene entre sus principales características la inclusión de los propietarios originales y una oferta diversa de vivienda: vivienda de remplazo para los propietarios, vivienda social y vivienda "libre".

La escala del proyecto ( 9 manzanas y alrededor de 10 hectáreas de suelo) permite dimensionar tanto las potencialidades como las complejidades de la renovación urbana y el reajuste de terrenos como formas para promover la oferta de suelo más equilibrado y diversa, tanto en relación con la composición de usos del suelo y la composición socioeconómica de sus beneficiarios, como en la forma de integrar y coordinar un conjunto amplio y diverso de actores públicos y privados. Con el fin de profundizar en los aspectos relevantes del caso, este trabajo hará, en primer lugar, una breve contextualización sobre el reajuste de terrenos, definiéndolo como instrumento y mostrando la forma en la que se inserta a la legislación urbana en Colombia. También, se habla sobre las formas tradicionales de gestión de suelo, la expropiación y el libre mercado, mostrando como el reajuste de terrenos se vuelve esa tercera vía para la gestión.

Después, se adentrará en el proceso del Plan Parcial, señalando las etapas del proceso de formulación, la caracterización general, socioeconómica y de la vivienda del área del proyecto. El análisis de la forma en la que se ha promovido la participación y deliberación entre un conjunto amplio de actores (propietarios, autoridades públicas, comerciantes, organizaciones barriales) tanto en la fase de formulación como de ejecución del proyecto pone en evidencia las virtudes y complejidades de nuevas formas de gobernanza urbana donde la interacción y coordinación entre diferentes actores son un medio para intentar conseguir resultados más equitativos e incluyentes en los procesos de renovación urbana en lugares centrales de la ciudad.

Por otro lado, se mostrará la propuesta urbanística general del plan, así como los objetivos y alcances de la oferta de vivienda, los esquemas y mecanismos de participación para los propietarios y residentes, las formas de gestión y financiación para la construcción y el avance actual del proyecto. Y, por último, se plantean las lecciones a modo de conclusión en dos temas; el acceso a vivienda y la gobernanza o participación ciudadana.

Los datos utilizados son los proporcionados tanto por los desarrolladores como por los participantes en el marco del proyecto, a través de una metodología que permite recoger la experiencia del proyecto en la medida que el autor ha hecho un seguimiento cercano de los principales hitos desde la etapa de formulación. También, se tienen en cuenta fuentes secundarias como los informes, las actas de concertación y las comunicaciones que los actores hacen a través de diferentes medios impresos y electrónicos.

El caso del Plan Parcial Fenicia logra mostrar un proyecto de renovación urbana enmarcado en la inclusión y la participación ciudadana, aspectos fundamentales para el éxito del reajuste de terrenos. Además, demuestra la necesidad de construir confianza entre los participantes, establecer reglas de juego claras, y tener en cuenta, incluso, a los actores que no se sientan a negociar. En pocas palabras, los buenos resultados que se pueden alcanzar cuando la ciudadanía activa forma parte de la formulación y ejecución de los proyectos que buscan una mejor ciudad.

\section{Abstract}

The main objective of this paper is to expose an example about the possibilities of land readjustment as a "third way" for land management and the availability of social housing in urban renewal projects. The example is a project situated in Bogotá's downtown, promoted by the Universidad de los Andes. The project is in its first step of execution, nevertheless,

${ }^{1}$ Director de JFP\& Asociados- Derecho Urbano. JFP\&Asociados. *Correo de contacto: ipinilla@ifpyasociados.com 


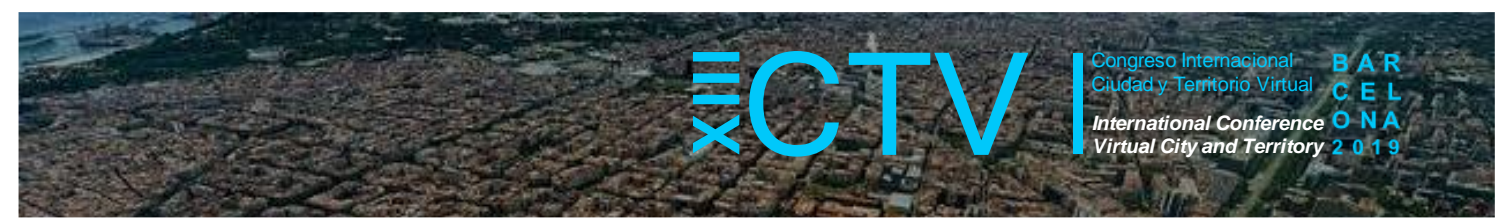

is a referent for the city because its opening and participative process for formulation and the innovations in its proposal of actors' association. The project includes the original owners as main participants and a diverse component of all kind of housing, like substitution housing, social housing and free housing for the developers and new residents.

The scale of the project ( 9 blocks and 10 hectares of land) allows to comprehend the potentialities and the complexities or urban renewal and land readjustment as ways to promote the diverse and balanced supply of land, by both in relation with the composition of land uses and the socioeconomic composition and in the way to integrate and coordinate a wide range of public and private actors. In order to expand the relevant issues of this case, this paper is going to do, in first place, a brief contextualization of land readjustment, defining it as a tool and showing its importance in the Colombian urban legislation. Also, it will talk about the traditional ways of land management, the expropriation and the free market, demonstrating how the land readjustment is that "third way" for the management.

Subsequently, it will show the Partial Plan process, pointing out the stages of formulation, the general, socioeconomic and housing characterization of the project area. The analysis of the way in which it be promoted the participation and deliberation between a wide range of actors (owners, public authorities, traders, communitarian organizations) in the formulation and execution stages of the project shows the virtues and the complexities of new ways of urban governance where the interaction and the coordination between different actors are a mode to try to achieve more equitable and inclusive results in the urban renewal process in the central places of the city.

On the other hand, the paper will show the general urbanistic proposal of the plan as long as the objectives and the scope of the housing supply, the owners and residents participation schemes and mechanisms, the ways of management, and financing for construction and the current progress of the project. And finally, the lessons are presented as a conclusion on two topics; access to housing and governance or citizen participation.

The data used is that provided by both the developers and the participants in the project, through a methodology that allows collecting the experience of the project to the extent that the author has closely followed the main milestones since the stage of formulation. Also, secondary sources such as reports, concertation minutes and the communications that the actors make through different printed and electronic media are taken into account.

The case of the Partial Phoenician Plan manages to show an urban renewal project framed in the inclusion and citizen participation, fundamental aspects for the success of the land readjustment. Furthermore, it demonstrates the need to build trust among the participants, establish clear rules of the game, and even take into account the actors who do not sit down to negotiate. In short, the good results that can be achieved when active citizenship is part of the formulation and execution of projects that seek a better city.

Palabras Clave: Renovación urbana; Reajuste de terrenos; Gentrificación; Gobernanza

Key words: Urban Renewal; Land Readjustment; Gentrification; Governance

\section{Introducción}

El Plan Parcial de Renovación Urbana "Triángulo de Fenicia" es un proyecto de renovación urbana ubicado en el barrio Las Aguas, en el centro histórico de la ciudad de Bogotá, zona que colinda con la Universidad de Los Andes. Pese a que el proyecto está en su primera fase de ejecución las características y principios que este tuvo, en su fase de formulación, lo han convertido en un referente en la ciudad. Esto se debe a que este proyecto tiene como principales características la inclusión de los propietarios originales y la oferta de vivienda en zonas de renovación urbana en el centro de la ciudad.

Con la expedición del Plan zonal Centro, entre el 2007-2012, se intensificaron los proyectos inmobiliarios en el centro de la ciudad. No obstante, los promotores privados de dichos proyectos tuvieron dificultades administrativas en el proceso de formulación. Por lo tanto, aunque algunos de estos proyectos no se ejecutaron, si produjeron un aumento de la especulación del precio del suelo en el centro de la ciudad que generaron procesos de gentrificación en este sector. Ante esta situación, a partir del 2012, se ve la necesidad de cambiar la aproximación del proceso de renovación urbana que se estaba llevando hasta el momento. La introducción de la política de "revitalización urbana" que se promovió desde la administración del momento, en donde se buscó proveer unidades de vivienda en el centro a bajo costo, y mantener el estrato y otras series de beneficios, tenía el fin de evitar cualquier tipo de exclusión en la ciudad. 


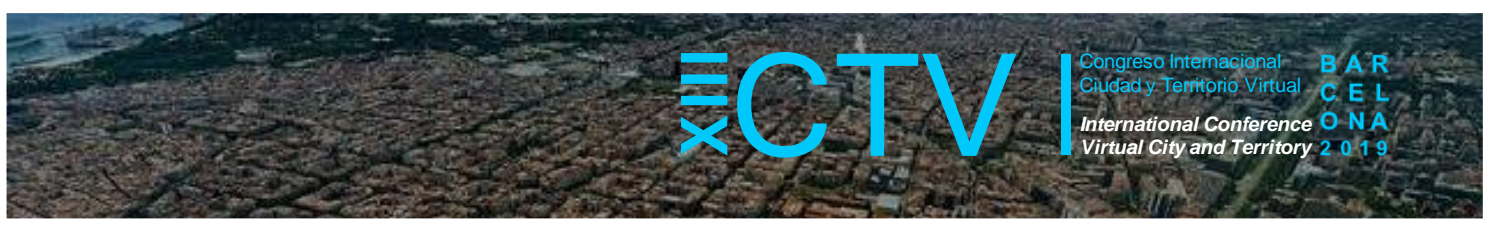

\section{El reajuste de tierras como mecanismo para la implementación de planes parciales de renovación urbana}

El reajuste de terrenos quedó formalmente incluido en Colombia a partir de la Ley 9 de 1989. Esta introduce este instrumento como un mecanismo que "(...) consiste en englobar diversos lotes de terreno para luego subdividirlos en forma más adecuada y dotarlos de obras de infraestructura urbana básica, tales como vías, parques, redes de acueducto, energía eléctrica y teléfonos"2. No obstante, fue solo luego de la expedición de la Ley 388 de 1997, en el marco de la implementación de los planes parciales y de la Unidades de Actuación Urbana (UAU), que se empieza a ver en la práctica los primeros efectos del reajuste de tierras en la gestión del suelo en Colombia.

Los planes parciales son instrumentos de planeación y gestión del suelo de escala intermedia que tienen como objetivo desarrollar ciertos sectores del suelo urbano y todo el suelo de expansión urbana. Tienen la función de: a) evitar el desarrollo predio a predio de la ciudad; b) determinar las condiciones de participación y los beneficios de los actores que intervienen en el plan; c) definir los tiempos y las etapas en las cuales se va a desarrollar el proyecto; d) establecer las necesidades de inversión, entre otros. Por otra parte, la UAU es la figura mediante la cual se implementa o desarrolla un plan parcial, puesto que delimita e integra uno o varios inmuebles para construir o urbanizar un proyecto en particular, garantizando el cumplimiento de las normas urbanísticas, la producción de bienes públicos y la gestión y participación de los propietarios.

En este sentido, el reajuste de tierras se establece como el mecanismo mediante el cual se define: a) la gestión asociada entre los propietarios del suelo para la ejecución de las UAU, siempre que al menos haya acuerdo de propietarios que representen al menos el $51 \%$ del área de la unidad; b) la posibilidad de uso de la expropiación contra los propietarios renuentes; c) se garantiza la distribución equitativa de las cargas y beneficios; $y$, d) se realiza la reconfiguración predial del área.

Figura 1. Esquema de operación de los instrumentos de planeación en Colombia

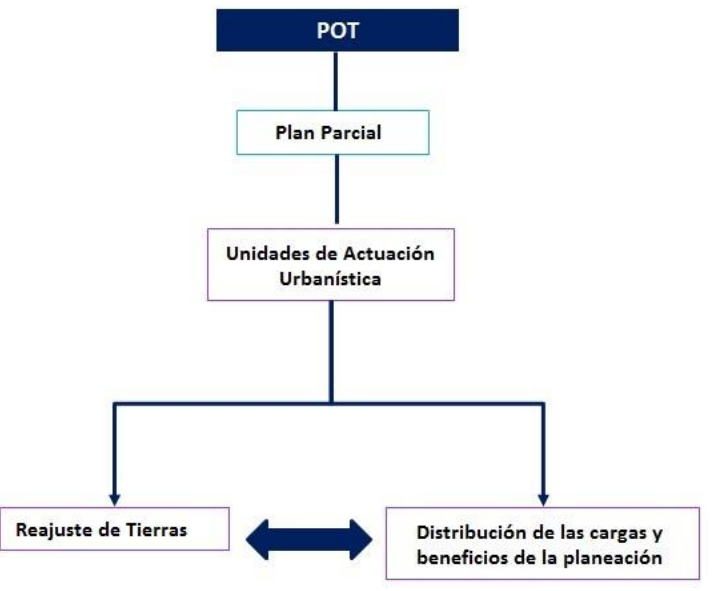

Fuente: Elaboración propia.

Generalmente, la expropiación y la compra de predios son los mecanismos de gestión del suelo que más se emplean para la gestión del suelo de proyectos de renovación urbana. No obstante,

${ }^{2}$ Ley 9 de 1989, artículo 77. 


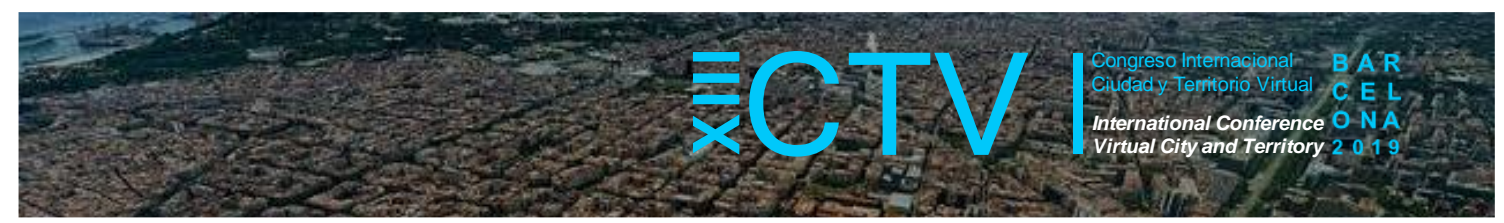

dichos mecanismos conllevan a la expulsión de la población original de dichas áreas hacia zonas con menor valor y de difícil accesibilidad, negando la posibilidad que los propietarios originales puedan gozar de los beneficios que trae consigo el proyecto (Hoyos \& Pinilla, 2015). Así mismo, resultan costosos y desgastantes puesto que requieren largos periodos para la resolución de litigios y el pago de elevadas sumas de dinero que dependerán de los resultados de las negociaciones entre promotores y propietarios. En este sentido, al comparar el reajuste de tierras con otros mecanismos de gestión del suelo, es evidente que el reajuste de tierras es la alternativa menos nociva y desgastante, en términos de tiempo y dinero, para llevar a cabo un proceso de desarrollo urbano.

\section{El Plan Parcial de Renovación Urbana Triángulo de Fenicia}

El Plan Parcial de Renovación Urbana Triángulo de Fenicia es un proyecto de renovación urbana promovido por la Universidad de los Andes, ubicado en el centro de la ciudad de Bogotá. Este plan parcial, busca transformar 8,8 hectáreas a través de la generación de oferta de vivienda, espacio público y la consolidación de centros de servicios y comercio empresariales. En este sentido, el plan parcial no sólo se enfoca en la producción de vivienda, sino en la transformación integral del área objeto del proyecto.

\subsection{Etapas del proceso de formulación del plan: el inicio hacia una planificación participativa}

Las discusiones en torno al tema de la renovación urbana en el país, han estado ligadas a la realización de ejercicios más inclusivos con los habitantes y moradores originales de zonas objetos de proyectos de este tipo. En este contexto, la Universidad de Los Andes, inicia la formulación del Plan Parcial Triángulo de Fenicia con el fin de ampliar su campus y poder dar cabida a la gran cantidad de estudiantes que buscan ingresar a este centro de educación superior. La gestión de este proyecto se puede dividir en dos etapas. Durante la primera etapa (2007-2010), la Universidad de Los Andes tomó la iniciativa para avanzar en la formulación de un proyecto, tomando en consideración exclusivamente sus expectativas y necesidades. Esta propuesta no avanzó mucho en su proceso de aprobación, debido a la inconformidad de los habitantes del sector con la propuesta inicial. Ante esta situación, Los Andes inició una segunda etapa (2010-2014), en la cual cambia fundamentalmente el enfoque de trabajo y estructura un nuevo esquema en donde se incluyen a los propietarios y residentes, vecinos del área de intervención, autoridades locales y comunidad universitaria.

El nuevo esquema se fundamentó en la planificación participativa en el cual se incluyó y se tuvo en cuenta los intereses de todos los actores involucrados en el proyecto, mediante mesas de trabajo. Como resultado, se logró que en el proyecto se contemplara la participación de los propietarios originales a través de un esquema de gobierno, alternativas de vinculación para moradores, esquemas de remplazo de los inmuebles y la producción de estrategias que evitaran la expulsión de los habitantes originales de la zona. Se buscó evitar eso en términos de los efectos del plan parcial en temas ligados al precio del suelo, estratificación ${ }^{3}$, así como la

\footnotetext{
${ }^{3}$ En Colombia, el cobro diferenciado de los servicios públicos domiciliarios se realiza a través de la estratificación socioeconómica, instrumento que permite establecer qué cantidad deben pagar los hogares según sus condiciones socioeconómicas. Este mecanismo permite la identificación de la capacidad de pago de los hogares, por medio de las condiciones físicas de la vivienda y la localización de ésta en la ciudad. Para su fácil ejecución, este sistema asigna un estrato de 1-6, siendo 1 las personas en una situación de más alta vulnerabilidad y 6 las viviendas con mayor capacidad adquisitiva. En el marco de del principio de solidaridad y el objetivo de redistribución, esta (Pinilla, 2016) clasificación tiene como fin que los hogares en estrato 5-6 y las tarifas impuestas a los usos comerciales, financien el precio total de
} 


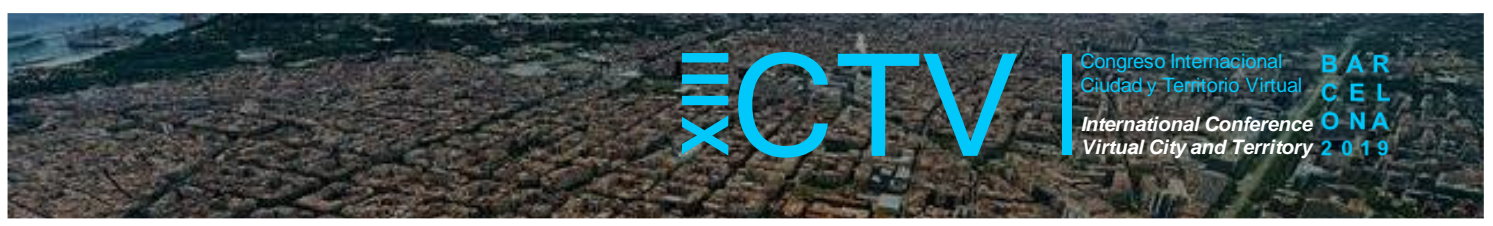

generación de programas económicos que ayuden a los gastos que tienen las familias que se localizan en este sector. A raíz de esto, se propuso la formulación de una política pública que estableciera acciones que evitaran dicho impacto, de esta forma se creó el Decreto Distrital 448 de 2014, en el cual se consignó las medidas para facilitar el proceso de formulación para los promotores privados de los proyectos, la inclusión de oferta de vivienda social, y, las medidas de protección e inclusión para los propietarios y moradores originales de las áreas objeto de planes parciales de renovación urbana en Bogotá.

En el caso del derecho preferencial, los planes parciales debían prever opciones de vivienda de remplazo con el fin de respetar el derecho de los propietarios y residentes de poder adquirir un predio en la propuesta de plan parcial de renovación. Para las compensaciones sociales, el decreto establece que los propietarios y moradores que se asocien al plan parcial, serán beneficiados con el pago de un canon de arrendamiento por el periodo de tiempo que se demore la ejecución de la UAU en donde se encuentre su vivienda de remplazo y el cubrimiento de los gastos de movilización de sus familiares y pertenencias a la ubicación temporal. En cuanto al mantenimiento del estrato original en lo inmuebles de remplazo, el decreto establece que para las viviendas de remplazo que correspondan a propietarios que están clasificados en los estratos 1,2 y 3 , les sea mantenido el estrato hasta por 10 años. Por último, para los subsidios de vivienda de hogares que se encuentran en alquiler, el documento contempla la asignación de un subsidio de vivienda hasta del $30 \%$ de la oferta de vivienda VIS y VIP que contemple el plan.

\subsection{Caracterización general del área del proyecto}

El área del proyecto comprende 9 manzanas y un total de 224 predios y se encuentra limitado por la Av. Circunvalar, la Av. Tercera, la Calle 20 y la Av. Jiménez, como se puede observar en la Figura 2.

Figura 2. Localización ámbito de aplicación plan parcial de renovación urbana Triangulo de Fenicia

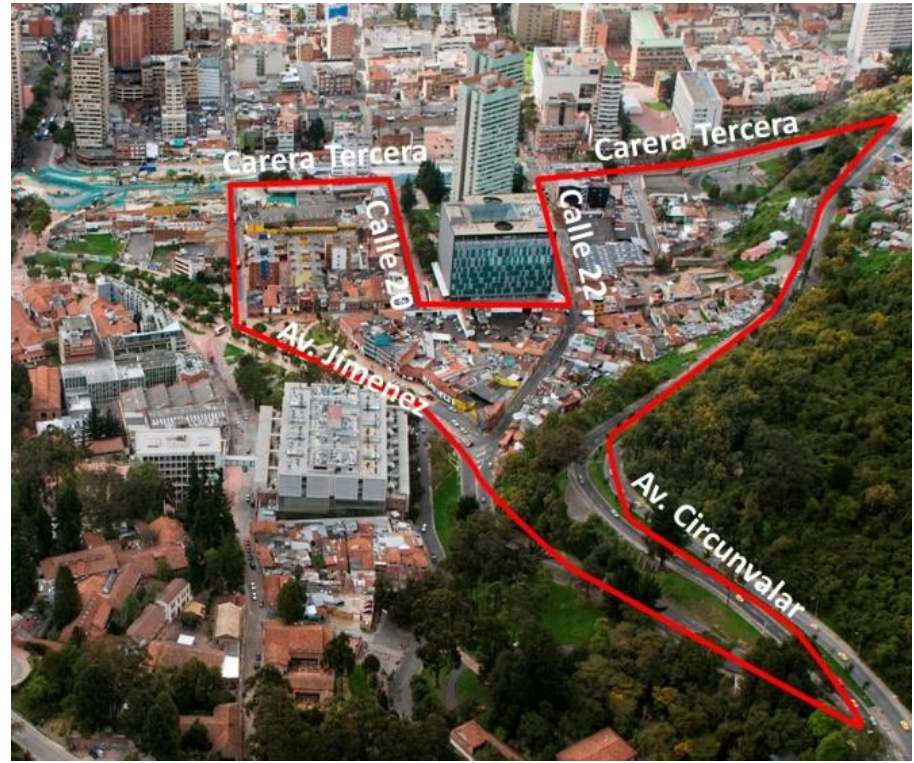

Fuente: Google Earth 2017-

los hogares que se encuentran en los estratos 1,2 y 3 . Para más información consultar: https://www.dane.gov.co/index.php/servicios-al-ciudadano/servicios-de-informacion/estratificacion-socioeconomica 


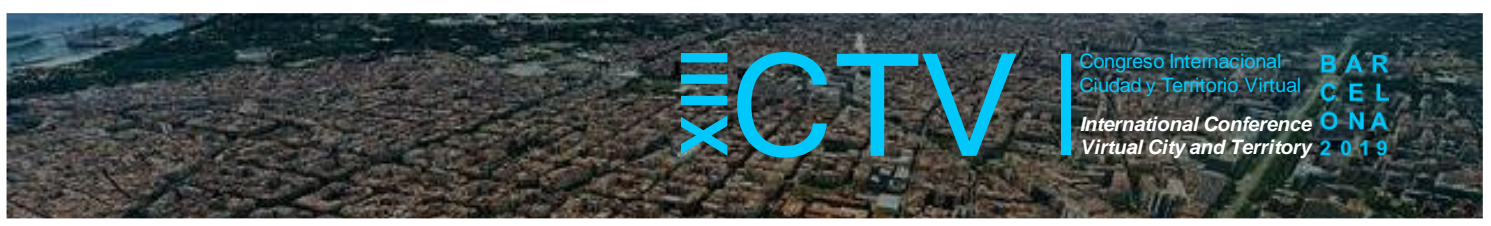

Con base en el $D T S^{4}$ del plan parcial:

- En esta área viven aproximadamente 460 familias.

- El $54 \%$ del suelo corresponde a vivienda, el $20 \%$ a parqueaderos en superficie, el $12 \%$ a comercio, y el $14 \%$ restante es de uso institucional e industrial.

- Existen aproximadamente 504 inmuebles, de los cuales 269 son propiedad horizontal.

- Y aproximadamente, de los 504 inmuebles existentes, 13 son de propiedad de la ciudad, 9 predios son de propiedad de la universidad de los Andes y el resto son de otros propietarios privados.

En total el plan parcial tiene un área bruta de $88.164,91 \mathrm{~m} 2$ (8,8 ha), de los cuales $13.821,86 \mathrm{~m} 2$ (1.3 ha) son área pública y $26.055 .01 \mathrm{~m} 2$ (2,6 ha) son área privada, como se puede observar en la Tabla 1.

Tabla 1. Cuadro General de áreas del Plan Parcial Triángulo de Fenicia

\begin{tabular}{|l|r|}
\hline \multicolumn{1}{|c|}{ Áreas } & \multicolumn{1}{c|}{ M2 } \\
\hline Total Área & $88.164,91 \mathrm{~m} 2$ \\
\hline Sistema General & $25.149,87 \mathrm{~m} 2$ \\
\hline Vías locales e intermedias & $16.157,37 \mathrm{~m} 2$ \\
\hline Control Ambiental Av. Circunvalar & $3.877,28 \mathrm{~m} 2$ \\
\hline Espacio Público & $13.821,86 \mathrm{~m} 2$ \\
\hline Equipamiento & $3.103 .52 \mathrm{~m} 2$ \\
\hline Área Privada & $26.055,01 \mathrm{~m} 2$ \\
\hline
\end{tabular}

Fuente: Decreto Distrital 420 de 2014 por medio del cual se adopta el Plan Parcial de Renovación Urbana "Triángulo de Fenicia", ubicado en la Localidad de Santa Fe y se dictan otras disposiciones.

\subsection{Caracterización socioeconómica del ámbito del proyecto}

Con base en la Encuesta de condiciones de vida realizada en 2011 por la Universidad de los Andes, se caracterizó el estado socioeconómico del área del proyecto a través de las siguientes variables:

a) Composición demográfica, actividad económica y ocupación laboral.

b) Estratificación socioeconómica.

Composición demográfica, actividad económica y ocupación laboral del área del proyecto. De acuerdo con la encuesta, en el barrio Las Aguas fueron encuestadas un total de 509 personas, de los cuales el $52 \%$ son mujeres. La mayoría de la población (el $49,3 \%$ ) que reside en el ámbito de aplicación, tiene menos de 15 años y/o entre los 15-29 años y de las 509 encuestadas que habitan en el barrio Las Aguas, el $55 \%$ de las personas trabajan como independientes, el $17 \%$ se dedica a oficios del hogar, el $5 \%$ es pensionado y el $10 \%$ está en busca de trabajo, como se puede observar en la Figura 3.

Figura 3. Condiciones socioeconómicas del barrio Las Aguas

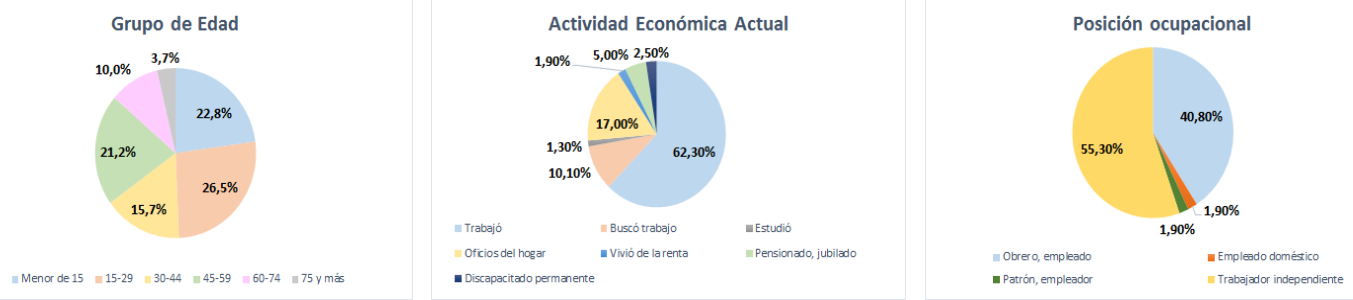

Fuente: Universidad de Los Andes (2012).

\footnotetext{
${ }^{4}$ Documento Técnico de Soporte anexo al Decreto Distrital por medio del cual se adoptó el Plan Parcial Triángulo de Fenicia.
} 


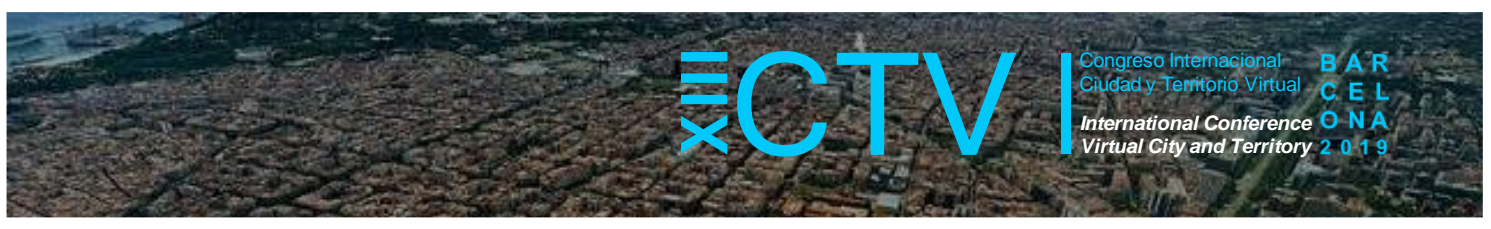

Estratificación socioeconómica del área del proyecto. En cuanto a la estratificación, como se puede observar en el plano de la izquierda, en la zona predominan los estratos 2 y 3 , lo que significa que las viviendas allí ubicadas corresponden a estratos bajos que albergan habitantes con menores recursos económicos, los cuales son beneficiarios de subsidios en los servicios públicos domiciliarios.

Figura 4. Estratificación socioeconómica del área del proyecto

Fuente: Elaboración propia.

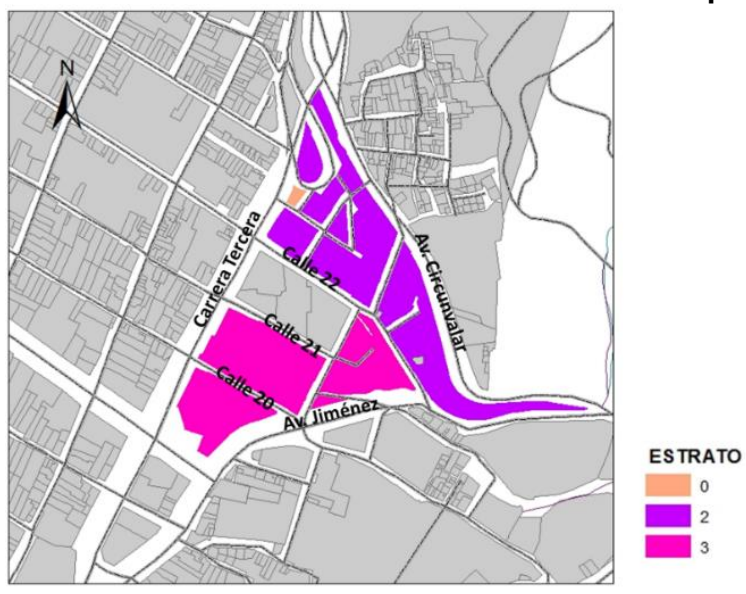

\subsection{Caracterización de la vivienda actual ubicada en el área del proyecto}

Con base en la Encuesta de condiciones de vida realizada en 2011 por la Universidad de los Andes, se caracterizó el estado de la vivienda actual del área del proyecto a través de las siguientes variables:
a) Tipología de la vivienda
b) Tenencia de la vivienda
c) Precio del suelo por $\mathrm{m}^{2}$
d) Precio de arriendo por $\mathrm{m}^{2}$

a) Tipología de la vivienda. Con base en la encuesta ya mencionada, se observa que el $50 \%$ de los inmuebles son casas, el $27 \%$ son apartamentos y el $22 \%$ son cuartos arrendados que se consideran como vivienda para las personas que habitan este lugar (ver figura 5).

b) Tenencia de la vivienda. En cuanto a la tenencia de la vivienda, de acuerdo con la misma encuesta, se observa que el $41 \%$ son propietarios, el $37 \%$ vive en arriendo y el $16 \%$ es poseedor u ocupante de hecho (ver figura 5).

Figura 5. Tenencia de la vivienda en el área del Plan Parcial Triángulo de Fenicia

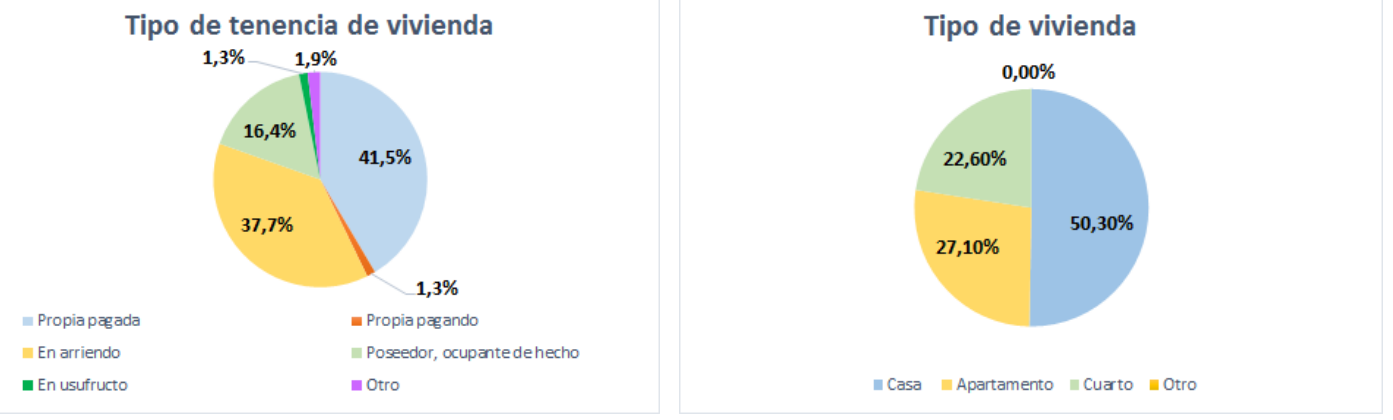

Fuente: Universidad de Los Andes (2012). 


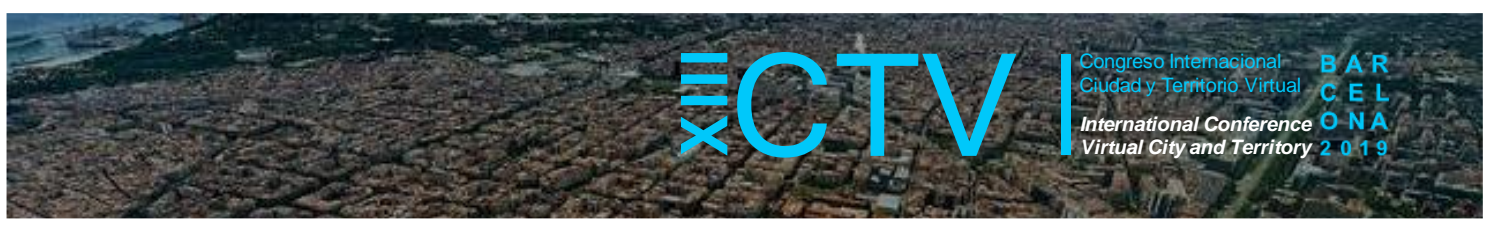

Adicionalmente, en la manzana 24 del área del proyecto, la cual se localiza al borde de la avenida circunvalar, se evidencia que existen viviendas sobre espacio público. El 100\% de la población que se encuentra en esta manzana se encuentra suscrita al SISBEN, lo que significa que estos hogares tienen condiciones socioeconómicas bajas. Los hogares que se localizan en esta área tienen ingresos económicos por debajo de los $\$ 700.000$ pesos colombianos ${ }^{5}$, de los cuales 6 de ellos tienen ingresos entre $\$ 100.000$ y $\$ 400.0000$ pesos. A continuación, se mostrarán algunos ejemplos de la zona anteriormente caracterizada.

Figura 6. Estado actual de las viviendas ubicadas en el espacio público dentro del plan
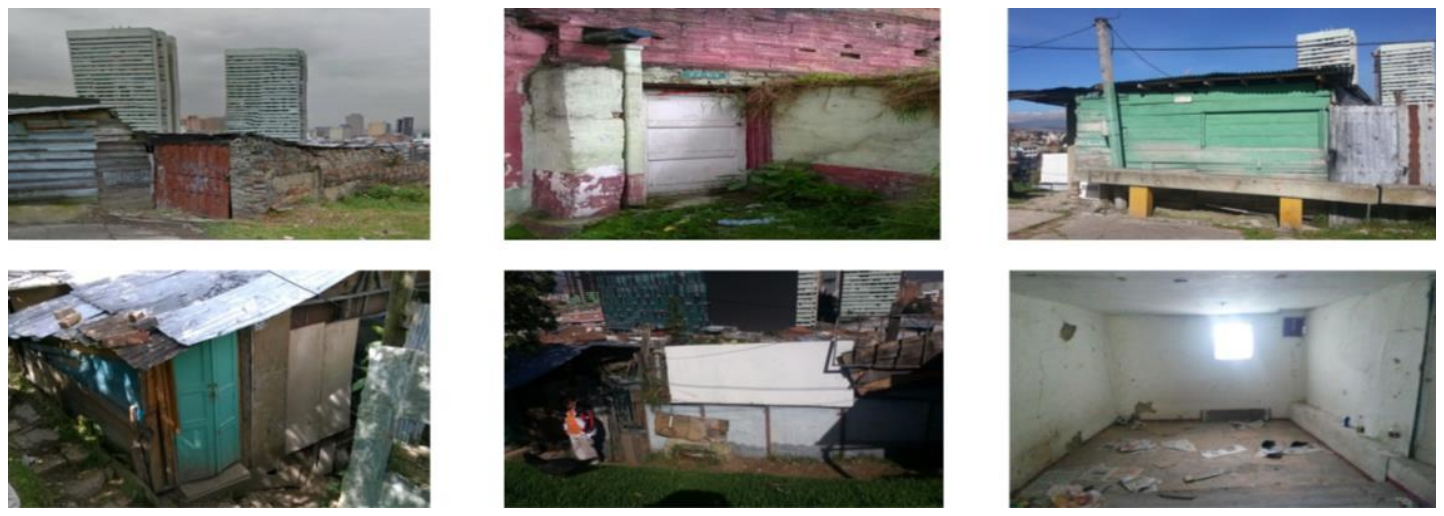

Fuente: Secretaría de Hábitat (2015).

c) Precio de referencia del suelo por $m^{2}$. Con base en la información suministrada por la Unidad Espacial de Catastro (UAECD), se pudo establecer que para el año 2014, los precios de referencia por $\mathrm{m} 2$ del área se encuentran entre los $\$ 240.000$ pesos a $\$ 1.100 .000$ pesos colombianos, dejando como promedio un valor de $\$ 701.818$ pesos.

d) Precio de arriendo por $\mathrm{m} 2$ del área del proyecto. Con base en la encuesta de calidad de vida realizada por la Universidad de los Andes, el precio por $\mathrm{m} 2$ de los arriendos del área del proyecto oscila según el tipo y el tamaño del inmueble (ver tabla 2).

Tabla 2. Tipo de predio arrendado y precio

\begin{tabular}{|c|c|c|c|}
\hline Manzana & $\begin{array}{l}\text { Tipo de predio } \\
\text { arrendado }\end{array}$ & $\begin{array}{l}\text { Precio } \\
\text { arriendo/m } \\
\text { es }\end{array}$ & $\begin{array}{l}\text { Precio en } \\
\text { dólares }\end{array}$ \\
\hline 25 & Casa & $\$ 300.000$ & US \$ 104 \\
\hline 13 & Apartamento & $\$ 1 ' 800.000$ & US \$ 621 \\
\hline 2 & Apartamento & $\$ 725.000$ & US \$ 250 \\
\hline 4 & Multifamiliares & $\$ 1 ' 100.000$ & US $\$ 380$ \\
\hline 2 & Apartamento & $\$ 750.000$ & US \$259 \\
\hline 12 & Cuarto en inquil & $\$ 240.000$ & US \$ 83 \\
\hline 25 & $\begin{array}{l}\text { Cuarto en } \\
\text { inquilinato }\end{array}$ & $\$ 250.000$ & US \$ 87 \\
\hline
\end{tabular}

Fuente: elaboración propia con base en datos tomados de Universidad de Los Andes (2012).

\section{Figura 7. Manzanas del Plan Parcial Triángulo de Fenicia}

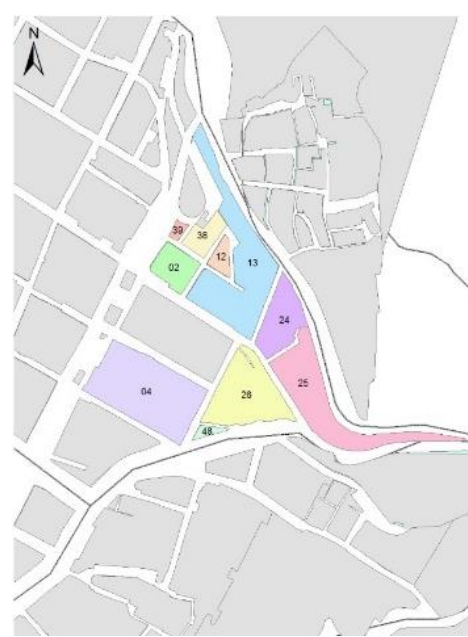

Fuente: Elaboración propia con datos de catastro.

${ }^{5}$ 378,99 USD (Para el año 2011, 1USD= \$ 1.847 COP). Fuente: Banco de la República de Colombia 


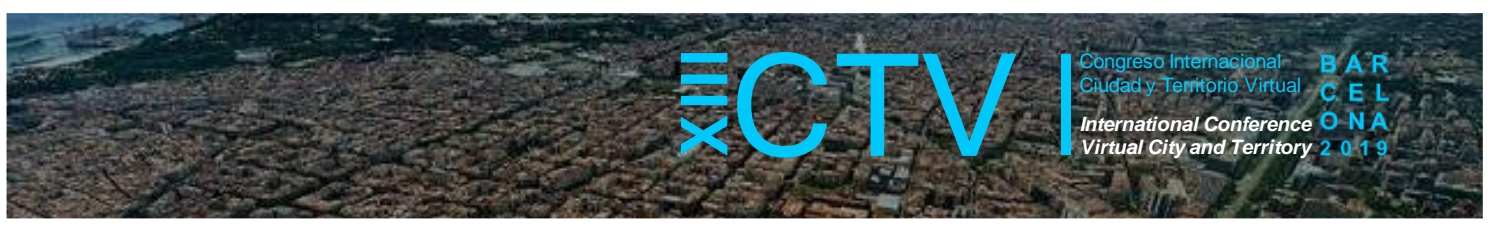

\subsection{Propuesta Urbanística general del Plan Parcial}

La propuesta urbanística de este plan parcial propone la mixtura de usos. En ese sentido, en las UAU se integran no sólo un uso, sino varios usos del suelo. En total se plantea la construcción de 1.603,13 m2 de comercio vecinal, 4.732,20 m2 de comercio zonal, 16.433,33 m2 de comercio metropolitano, 13.175,00 m2 de servicios personales, 22.950,00 de servicios empresariales, $67.942,13 \mathrm{~m} 2$ de vivienda y $21.675,00 \mathrm{~m} 2$ de dotacional metropolitano, como se puede observar en la Figura 8.

Figura 8. Propuesta de diseño y usos del Plan Parcial de Renovación Urbana Triángulo de Fenicia Propuesta de usos Propuesta de diseño
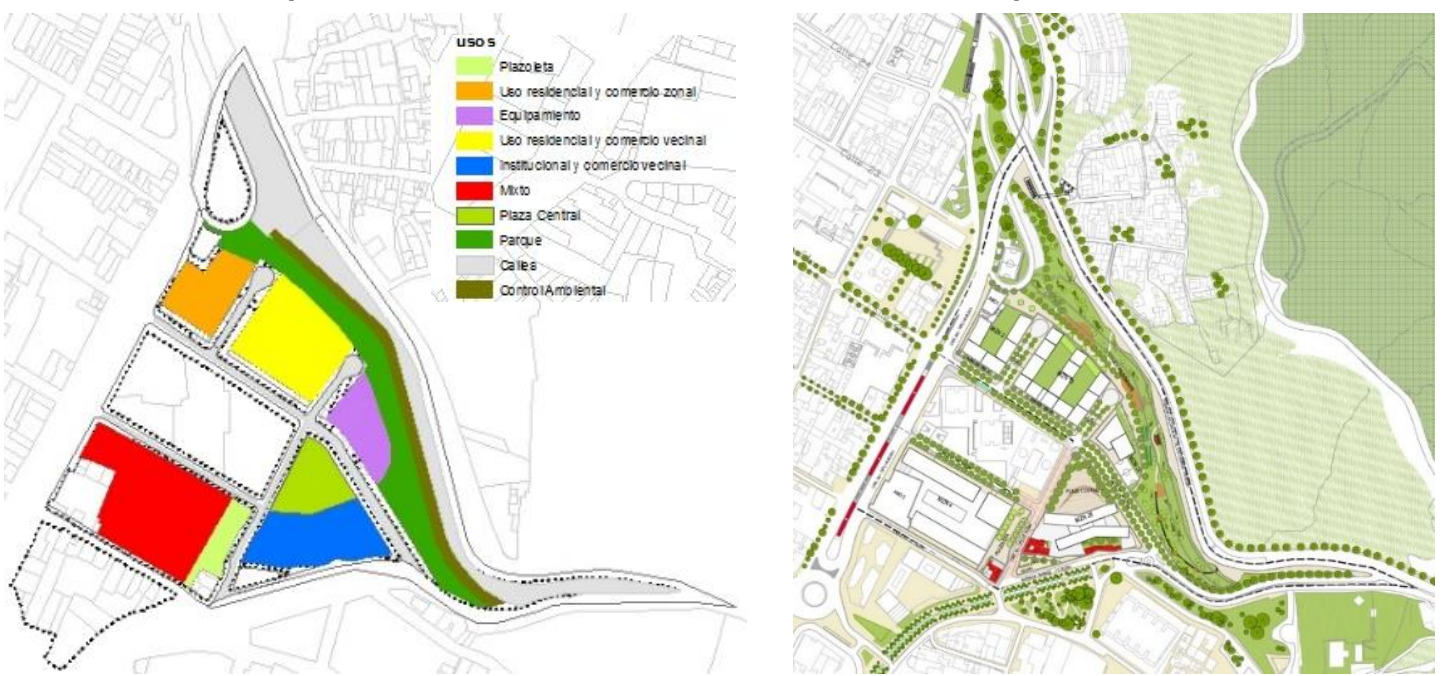

Fuente: elaboración propia con base en el Decreto 420 de 2014. Universidad de los Andes (2014)

\subsection{Objetivos y alcances de la oferta de vivienda en el plan parcial}

Uno de los componentes y objetivos del plan parcial es promover la oferta de vivienda por medio de la renovación urbana. Para ello, en el proyecto se propone la construcción de 946 unidades de vivienda distribuidas como se muestra en la Tabla 3.

Tabla 3. Tipo de viviendas del Plan Parcial Triángulo de Fenicia

\begin{tabular}{|l|r|}
\hline Tipo de Vivienda & Cantidad \\
\hline Vivienda de remplazo & 400 \\
\hline Vivienda de Interés Social & 108 \\
\hline Vivienda restante para venta & 438 \\
\hline Total & 946 \\
\hline
\end{tabular}

Fuente: Universidad de Los Andes (2014)

En este sentido, la oferta de vivienda ofrecida en el plan parcial está dirigida a los propietarios originales y a los poseedores de los predios que se encuentran en el ámbito del plan parcial, con el fin de garantizar su permanencia y evitar su desplazamiento hacia otras zonas de la ciudad. De acuerdo a las encuestas de calidad de vida realizadas en el barrio Las Aguas, por parte de la Universidad de Los Andes, se pudo establecer que los predios que se encuentran en situación de ocupación son 16,4\%. De este porcentaje, se desprenden dos tipos de situaciones; la primera 


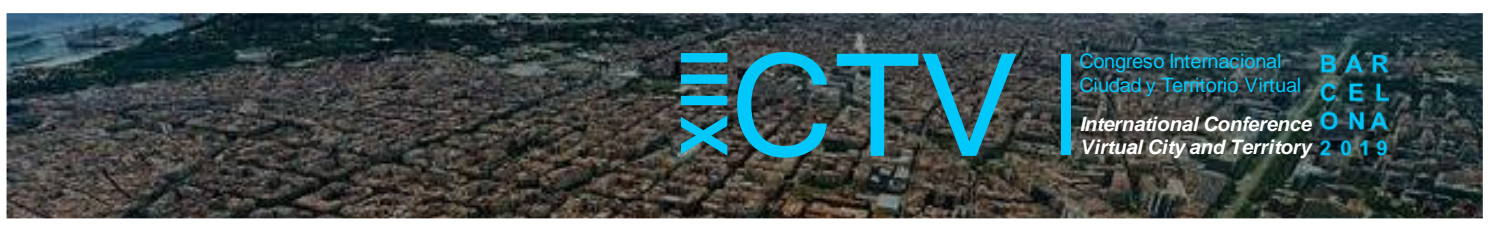

es la de poseedores que llevan más de 10 años de posesión pacífica quienes pueden regularizar su situación, y la segunda, en la cual se encuentran alrededor de 49 personas que conforman 15 hogares, ocupando áreas que corresponden a espacio público.

En el caso de los poseedores con más de 10 años, estos gozarán de los mismos beneficios que cualquier propietario, siempre y cuando inicien el proceso de regularización de sus predios y estos lleguen a buen término. En cuanto a las familias que ocupan espacio público, en el marco legal colombiano de la propiedad, no es posible que estos sean reconocidos como propietarios en el plan, por lo que la propuesta de viviendas de restitución no es posible para este porcentaje de hogares que residen en la zona.

Esta situación restringe la estancia de estas familias en la zona por medio de la adquisición de un subsidio de vivienda que les permita obtener una de las unidades de vivienda VIS ofrecidas en el plan parcial. Esto solo puede pasar si la familia que piensa acceder a esta oferta, cumple con las condiciones que establece el sistema de subsidios distritales para acceder a vivienda tipo social. Lo anterior no constituye una solución estructurada, dejando en evidencia una de las limitaciones del plan, la cual es no poder contar con una medida efectiva para la estancia de esta población particular en el área.

\subsection{Esquemas y mecanismos de participación para los propietarios y no propietarios} de vivienda que se encuentran en el ámbito del plan parcial

El plan parcial establece el siguiente esquema de participación para los propietarios y no propietarios de vivienda que se encuentran en el ámbito del plan parcial.

\section{Figura 9. Esquema de participación para los propietarios y no propietarios del} suelo en el Plan Parcial Triángulo de Fenicia

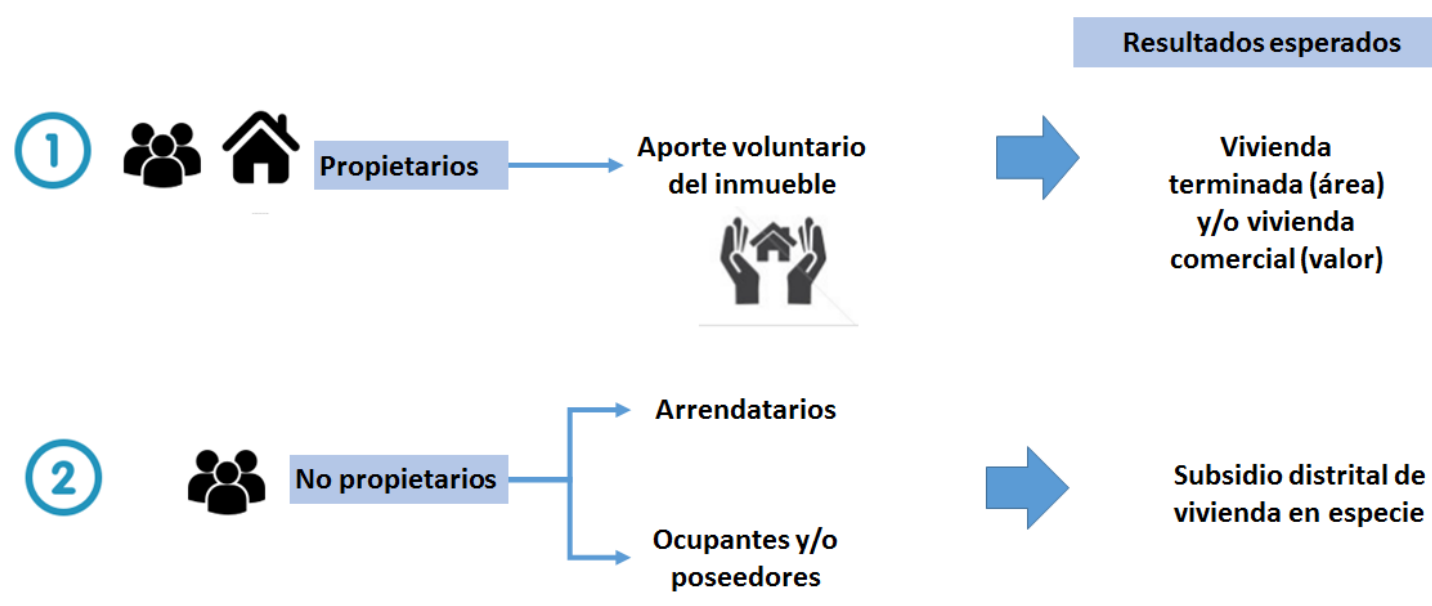

Fuente: elaboración propia

Para los propietarios originales del predio y/o de los inmuebles que se encuentran en el ámbito del plan parcial, se establece un mecanismo de participación de intercambio de áreas m2 a m2, de acuerdo con el aporte voluntario del predio y/o inmueble de su propiedad.

Para llevar a cabo lo anterior, se establecieron los siguientes criterios de aporte y remuneración acordes con la tipología de la vivienda aportada: 


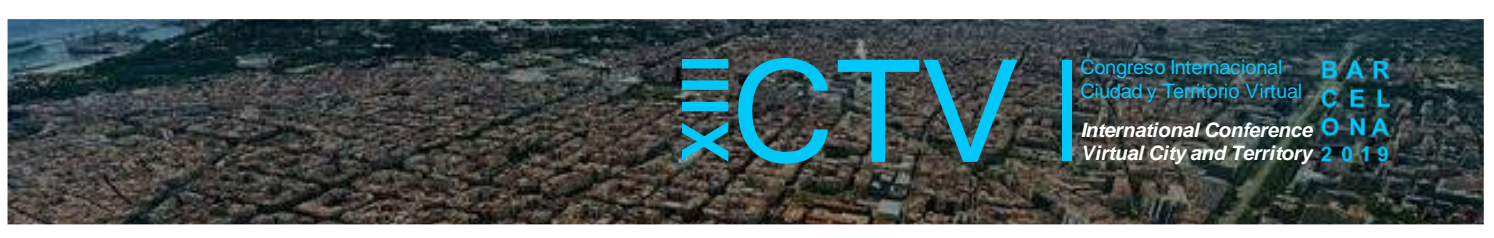

Tabla 4. Criterios para el reajuste de tierras del área de aplicación del Plan Parcial Triángulo de Fenicia

\begin{tabular}{|c|c|}
\hline $\begin{array}{l}\text { Tipología de la vivienda } \\
\text { aportada al plan parcial }\end{array}$ & Criterios de aporte y remuneración \\
\hline Apartamento & $\begin{array}{l}\text { Remplazo de } 1 \mathrm{~m} 2 \text { de vivienda de reemplazo por cada m2 de área } \\
\text { construida del inmueble aportado. }\end{array}$ \\
\hline Vivienda Productiva & $\begin{array}{l}\text { Reemplazo de } 1 \mathrm{~m} 2 \text { de vivienda de reemplazo por cada } \mathrm{m} 2 \text { de área } \\
\text { construida de vivienda del inmueble aportado. Y una relación de } \\
\text { reemplazo de } 1 \mathrm{~m} 2 \text { de comercio de reemplazo por cada } \mathrm{m} 2 \text { de área } \\
\text { construida de comercio efectivo del inmueble aportado. }\end{array}$ \\
\hline $\begin{array}{l}\text { Casa tipo } 1 \text { (Área ocupada } \\
\text { igual al área del terreno) }\end{array}$ & $\begin{array}{l}\text { Reemplazo de } 1 \text { m2 de vivienda de reemplazo por cada m2 de área total } \\
\text { construida del inmueble aportado. }\end{array}$ \\
\hline $\begin{array}{l}\text { Casa tipo } 2 \text { (Área ocupada } \\
\text { menor que el área del } \\
\text { terreno) }\end{array}$ & $\begin{array}{l}\text { Reemplazo de } 1 \mathrm{~m} 2 \text { de vivienda de reemplazo por cada } \mathrm{m} 2 \text { de área } \\
\text { construida del inmueble aportado. Adicionalmente la diferencia entre el } \\
\text { área del terreno y el área ocupada, se compensará siguiendo el mismo } \\
\text { criterio establecido para lote con servicios. }\end{array}$ \\
\hline $\begin{array}{l}\text { Lote con servicios } \\
\text { (exceptuando los } \\
\text { parqueaderos) }\end{array}$ & $\begin{array}{l}\text { - Para los lotes de servicio con sus características topográficas, forma } \\
\text { tamaño y localización tienen un valor comercial mayor y facilitan que } \\
\text { el proyecto pueda ejecutar en tiempos más cortos, evitando el } \\
\text { impacto de costos que se generan por traslados temporales de los } \\
\text { moradores, Se reconoce una equivalencia de reemplazo de } 0,7 \mathrm{~m} 2 \\
\text { construidos de comercio zonal por cada m2 de suelo libre. } \\
\text { Para los demás lotes con servicios se reconoce una equivalencia de } \\
\text { reemplazo de } 0,5 \mathrm{~m} 2 \text { construidos de comercio zonal por cada m2 de } \\
\text { suelo libre. }\end{array}$ \\
\hline
\end{tabular}

Fuente: elaboración propia con base en el DTS del Plan Parcial Triángulo de Fenicia.

Ahora, para ambos casos, de poseedores privados y de ocupantes de espacio público, a través del artículo 11 del decreto distrital 448 de 2011, se estableció la priorización de la asignación del subsidio distrital de vivienda en especie en proyectos de renovación urbana en la ciudad, mediante el cual se esperaba que los arrendatarios originales del ámbito del proyecto pudieran acceder a la Vivienda de Interés Social (VIS) proyectada en el proyecto.

No obstante, en diciembre de 2016, este artículo se derogó a través del Decreto Distrital 623 "Por el cual se establece el Programa Integral de Vivienda Efectiva y se dictan otras medidas para la generación de vivienda nueva y el mejoramiento de las condiciones de habitabilidad y estructurales de las viviendas y se dictan otras disposiciones". Por lo tanto, la oferta de vivienda para los habitantes originales del ámbito de aplicación del plan parcial que no son propietarios (arrendatarios y/o poseedores) es nula, debido precisamente que la política de vivienda Distrital se ha enfocado en ofrecer alternativas de solución de vivienda nueva en suelos no objeto de renovación urbana.

\subsection{Esquema de gestión y financiación para la construcción de las unidades de vivienda propuestas en el Plan Parcial Triángulo de fenicia}

El proyecto, se financiará a través del reparto de cargas y beneficios del mismo. Las cargas son las obras de urbanismo a ejecutar en cada etapa y los beneficios son la edificabilidad que tiene acceso cada etapa. Algunas UAU tienen mayores beneficios, es decir, mayor edificabilidad.

Por lo tanto, éstas serán las encargadas de asumir las cargas de las UAU que tienen la suficiente capacidad financiera para pagar sus cargas. De esta manera, es posible financiar la totalidad de las obras del plan, como se muestra en la Figura 10. 


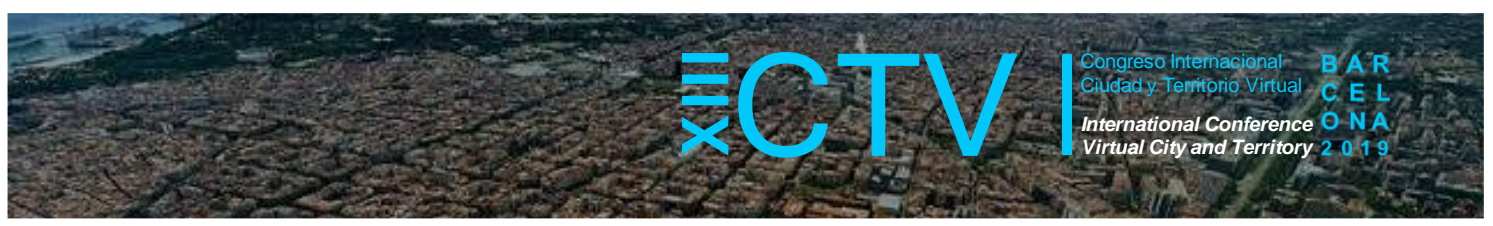

Figura 10. Sistema de reparto de cargas y beneficios del Plan Parcial Triángulo de Fenicia

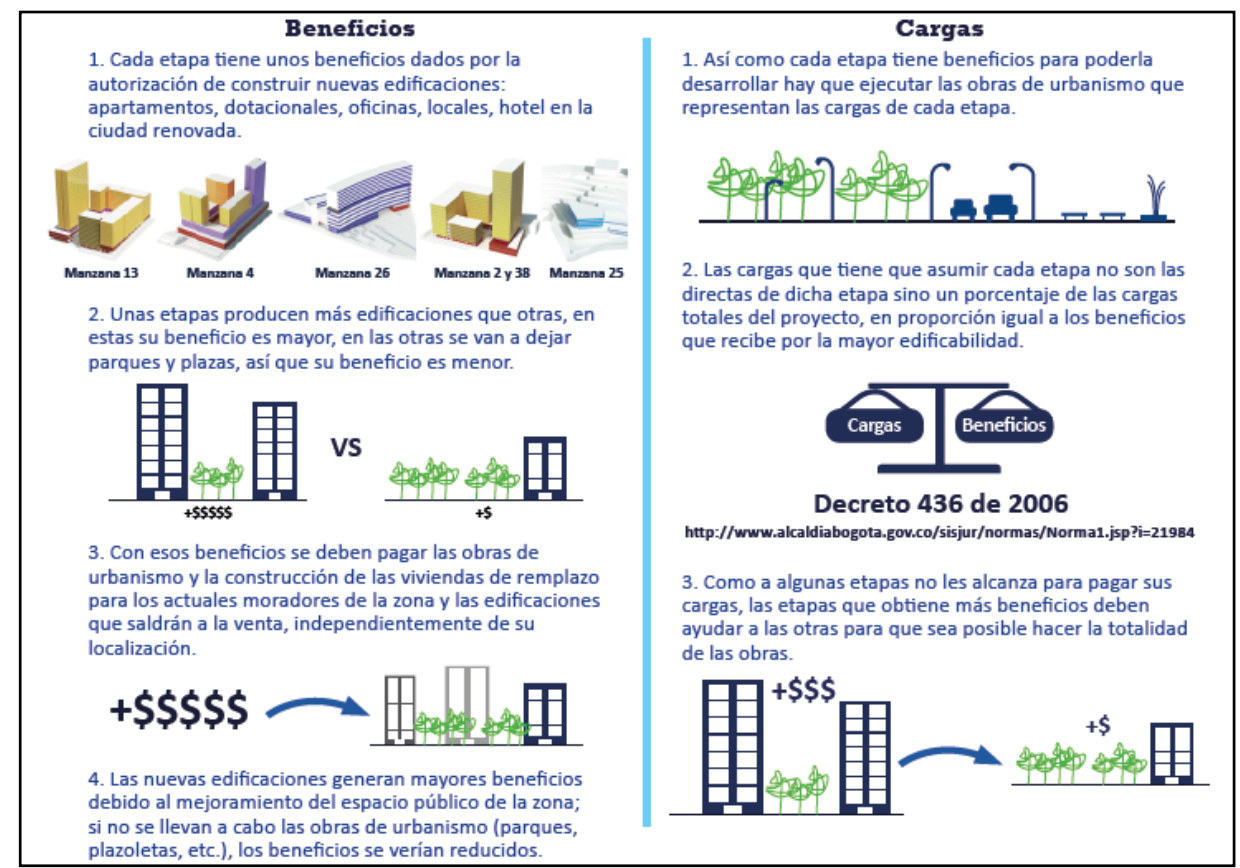

Fuente: Universidad de los Andes - Programa Progresa Fenicia. "Bases para la actuación de la Unidad de Actuación Urbanística No. 1." Julio 7 de 2016.

A fin de garantizar la distribución equitativa de los costos y beneficios y facilitar los mecanismos de gestión asociados entre los propietarios, la propuesta establece que la gestión de la tierra se realizará a través de cinco UAU distintas que agrupan bloques y lotes como se muestra en la Tabla 5.

Tabla 5. Áreas y composición de las Unidades de Actuación Urbanística propuestas

\begin{tabular}{|l|c|c|c|}
\hline UAU & $\begin{array}{l}\text { Área privada } \\
\text { aproximada } \\
\text { (catastro 2013 m2) }\end{array}$ & $\begin{array}{l}\text { Número de } \\
\text { manzana }\end{array}$ & $\begin{array}{l}\text { Número aproximado de casas } \\
\text { unifamiliares, apartamentos y } \\
\text { lotes }\end{array}$ \\
\hline UAU_01 & 6,332 & 13 & 15 \\
\hline UAU_02 & 13,864 & 4 & 224 \\
\hline UAU_03 & 8,717 & 26 & 49 \\
\hline UAU_04 & 12,773 & 24,25 & 64 \\
\hline UAU_05 & 11,019 & $2,12,13,38,39$ & 130 \\
\hline Total & 52,705 & &
\end{tabular}

Fuente: Universidad de los Andes, 2014.

El propósito de las UAU, es garantizar un uso adecuado y la provisión de la infraestructura necesaria para la renovación del ámbito de aplicación del plan parcial. A pesar de que la transformación se llevará a cabo en etapas, la distribución equitativa de los costos y beneficios será compartida entre todas las propiedades y propietarios involucrados. Habrá un fideicomiso encargado de regular y finalizar esta distribución equitativa entre todas las unidades. Se ha calculado que la proporción global de contribución de tierras en el programa de reajuste de tierras será alrededor del 50 por ciento. El mecanismo legal que se utilizará en las UAU será un esquema de fideicomiso mercantil mediante el cual se constituyen un fideicomiso principal y cinco fideicomisos subordinados a la misma para llevar a cabo la inclusión de las unidades inmobiliarias 


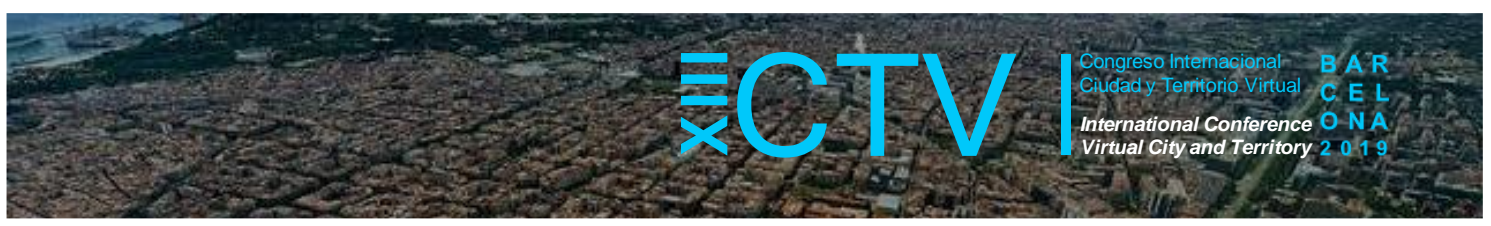

de UAUs. Los propietarios, el promotor del proyecto y los inversionistas participarán en este esquema, así como el gobierno de la ciudad a través de la Empresa de Renovación Urbana (ERU).

Figura 11. Esquema de gestión del Plan Parcial Fenicia

\section{Land Trust Scheme}

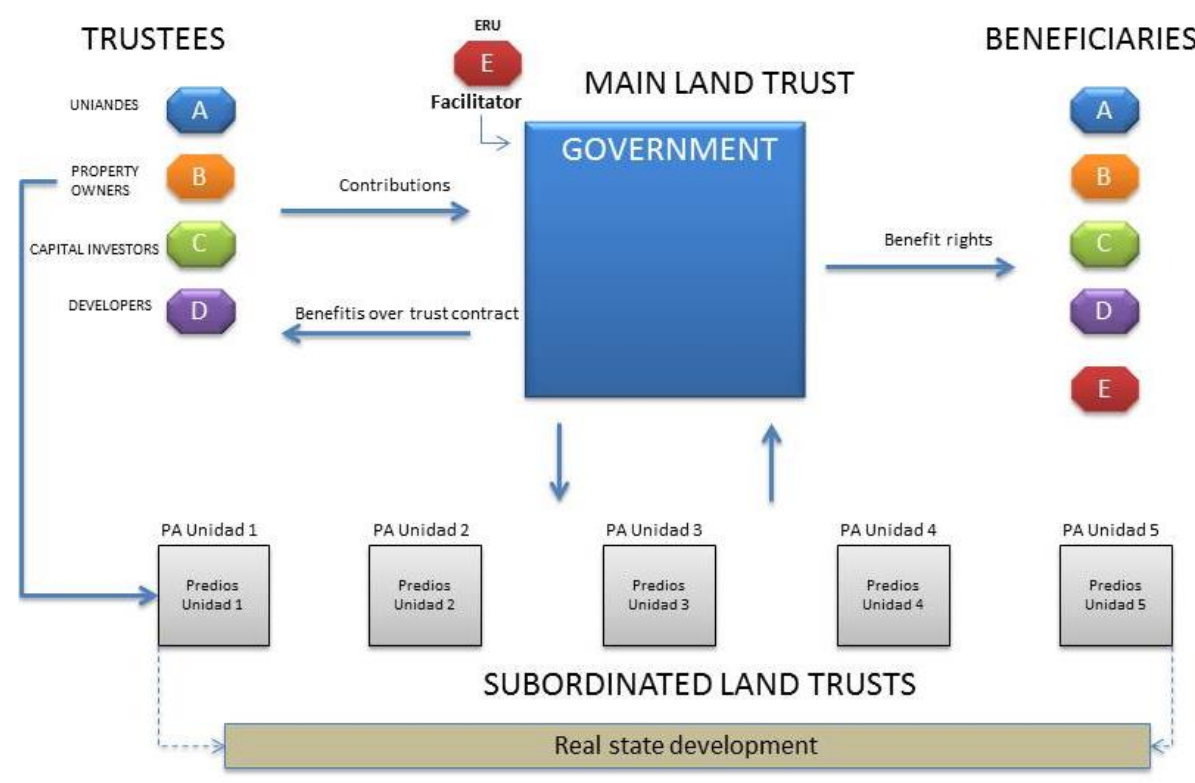

Fuente: Documentos Alianza Fiduciaria.

El régimen de fideicomiso permite que los propietarios participantes se conviertan en socios en el proyecto y compartan sus beneficios. El marco retributivo básico para el programa de reajuste de tierras se basa en la zona actualmente construida. Es importante señalar que este esquema de reajuste de tierras basado en áreas fue el resultado de dos circunstancias que quedaron claras durante el proceso de formulación. Por un lado, había una necesidad de atraer a propietarios de apartamentos para participar en el proyecto. Por otro lado, las controversias y demandas podrían conducir a cambios en la definición de los valores de mercado actuales de las propiedades. A través de la discusión con los propietarios, el esquema estaba cambiando de un enfoque basado en valores a un esquema basado en áreas.

3.9 Avances y estado actual de la implementación del mecanismo de reajuste de tierras en el cumplimiento de los objetivos de vivienda en el Plan Parcial Triángulo de Fenicia

El Plan Parcial, mediante el cual se ejecuta el proyecto, ya está aprobado. Actualmente se encuentran delimitadas tres unidades de actuación (1, 3 y 4) y hay acuerdos de bases para la actuación en dos de ellas (la 2 y la 4). En ambas los acuerdos de los propietarios sobre las bases para la actuación son superior al $90 \%$. También, ya se cuenta con licencia de urbanismo en la modalidad de reurbanización para la UAU No. 1. Con esa licencia se pueden comenzar las obras para el desarrollo del proyecto, iniciando así el proceso de implementación. 


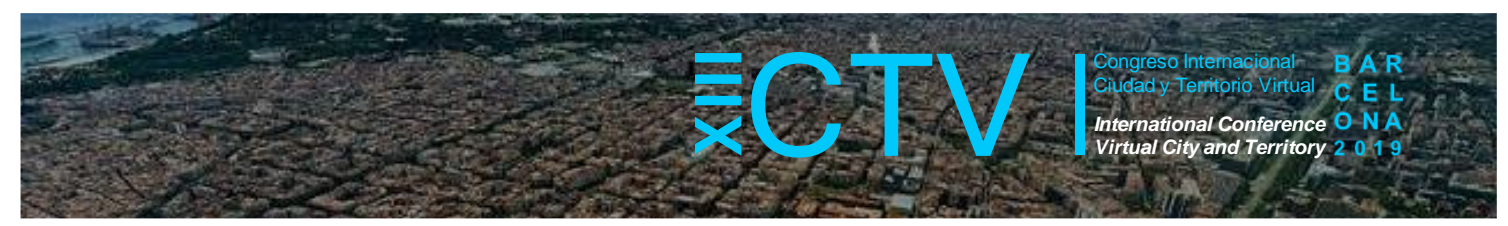

Por otro lado, el promotor del proyecto convocó a desarrolladores privados a vincularse al proyecto como constructores de las obras de urbanismo y de las unidades inmobiliarias. Después de un proceso de más de 6 meses recientemente se eligió al desarrollador que está conformada por un consorcio entre tres importantes firmas de construcción en Colombia. De esta manera se puede evidenciar el éxito que ha tenido la estrategia de gestión, la cual ya permitió los acuerdos que dan paso a la renovación.

\section{Conclusiones}

Aunque el plan parcial no ha finalizado su ejecución, ya puede mostrar varias lecciones sobre el reajuste de terrenos. En ese sentido, estas conclusiones se enfocarán en dos temas principales, la gobernanza y el acceso a vivienda para personas con condición socioeconómica desfavorable. Sobre el primer tema, es importante resaltar el proceso que llevó a cabo el plan parcial en términos de participación, dedicando buena parte del tiempo a la concertación con propietarios y a la definición de las reglas básicas de ingreso al proyecto como participante. Este plan parcial es el ejemplo de cómo "el reajuste de terrenos puede ser un medio para promover nuevas formas de participación ciudadana y gobernanza urbana que corrija, al menos en parte, los déficits de participación y consulta que tienen otros proyectos" (Hoyos \& Pinilla, 2015, p.236). Lo anterior en la medida que vincula a los habitantes no en términos abstractos, como los procesos tradicionales, sino en términos de alcanzar un objetivo concreto.

El reajuste de terrenos es un instrumento que fortalece la gobernanza de forma tal que ayuda a fortalecer y consolidar estructuras de participación y acción comunitarias. Contrario a lo que se puede pensar, el reajuste de terrenos no tiene como condición la existencia de organizaciones vecinales fuertes o articuladas. Lo que muestra el caso de Fenicia es que, en una comunidad dispersa y no tan consolidada, se fortalece la participación de los ciudadanos ya que se dan nuevos liderazgos, nuevos escenarios de gestión y más oportunidades de inclusión de distintos actores.

Por otro lado, otra de las lecciones que deja Fenicia es la necesidad de construir confianza entre los participantes como condición inherente al éxito del proyecto. Para llegar a altos niveles de credibilidad entre los participantes Fenicia implementó la formalización de documentos donde se manifestaba la buena voluntad y se plasmaban los acuerdos a los que se llegaban. También, se estableció un plan de negociación claro y homogéneo, de tal forma que los participantes estuvieran en igualdad de condiciones. Todas estas estrategias muestran que sí es posible construir confianza entre los actores, haciéndolos partícipes y dejando en claro qué aspiraciones puede llegar a tener cada uno.

Ligado a lo anterior, vale la pena resaltar que el caso Fenicia muestra que la negociación entre actores es fundamental en las fases de formulación y diseño de un proyecto, no solo en la de aprobación o implementación. Esto se refleja en los numerosos cambios que sufrió el proyecto desde su formulación inicial, cambios que enriquecieron el proyecto y que permitieron llegar a resultados que beneficiaran a más propietarios. Si no se hubiera tenido en cuenta esos cambios sugeridos por los actores la viabilidad del proyecto se hubiera puesto en riesgo, esto al no tener el apoyo requerido para poder llevar a cabo el proyecto.

Con respecto al acceso de vivienda en esta zona de la ciudad, que con la renovación urbana y el plan del 2007 se volvió un área de alta especulación inmobiliaria, se debe hacer énfasis en el modelo que siguió Fenicia, en el que se reconocía a los propietarios y a los ocupantes de hecho 


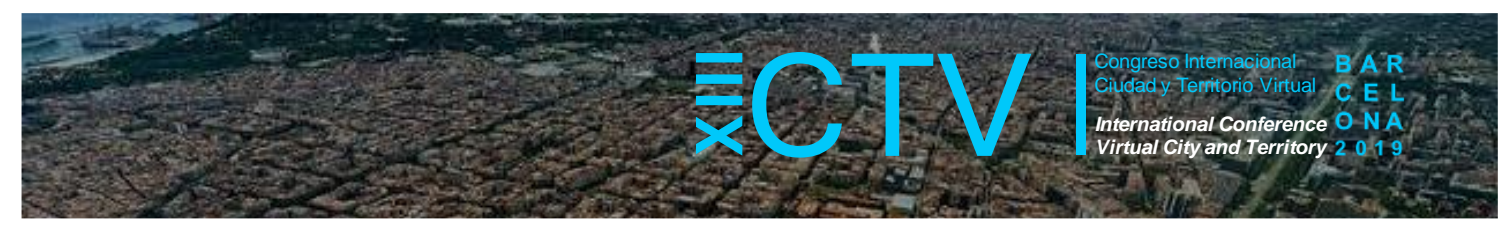

que tuvieran cierta antigüedad en la zona. Este esquema donde se invitaba a estos participantes a regularizar su tenencia para participar del proyecto muestra una estrategia donde se conserva a los residentes, y, además, se evita su futuro desplazamiento. Esto, junto a la política de viviendas de reemplazo en el mismo lugar hace que los sectores menos favorecidos no solo participen del desarrollo urbano, sino que adicionalmente puedan compartir sus beneficios.

El Plan Parcial Triángulo de Fenicia es innovador en el campo de la renovación urbana, debido a su proceso de gestión y acompañamiento con la comunidad. No obstante, por esta misma condición, se requiere de una evaluación que permita dar cuenta de sus aciertos y limitantes, para futuros ejercicios que se decidan por realizar un proceso de renovación urbana incluyente, que aplique el reajuste de tierras como mecanismo de gestión del suelo. En síntesis, el Plan Parcial ha mostrado la utilidad del reajuste de terrenos como herramienta de gestión del suelo, la cual, más que tener ventajas en la dimensión de adquirir suelo o financiar obras, que pueden ser cubiertas por otros instrumentos, permite procesos reales de gobernanza, participación ciudadana, inclusión, y construcción comunitaria de una mejor ciudad.

Agradecimientos: Esta ponencia es fruto de un proyecto financiado por el Lincoln Institute of Land Policy; agradecimientos especiales a la Universidad de los Andes y al Fideicomiso Triángulo de Fenicia. El autor ha estado involucrado en el proyecto desde su fase de formulación.

\section{Bibliografía}

Catastro. (23 de mayo de 2017). Unidad Administrativa Especial de Catastro de Bogotá. Obtenido de Unidad Administrativa Especial de Catastro de Bogotá. Recuperado de https://www.catastrobogota.gov.co/es/consulte-el-valor-de-referencia-del-metro-cuadrado-delos-predios-de-bogota

Daza, R. (15 de septiembre de 2015). Issu. Recuperado de https://issuu.com/ricardodaza2/docs/daza2015 testing land readjustment

Departamento Nacional de Planeación. (2015). Curso interacional: política urbana y gestión de proyectos integrales. Bogotá: DNP.

Flórez, C. E. (2011). Encuesta de condiciones de vida 2011. Bogotá.

Hábitat, S. d. (2015). Caracterización Ocupaciones Predio 13 de espacio público. Plan Parcial Fenicia. . Bogotá: Borrador.

Hoyos, C., \& Pinilla, J. F. (2015). El reajuste de terrenos: una alternativa más equitativa e incluyente para la gestión del suelo en procesos de renovación urbana. En Secretaría de Planeación Distrital, De la renovación a la revitalización; desafíos para Bogotá (págs. 180-197). Bogotá: Bogotá Humana.

Niño Sicard, G. (2015). La participación en renovación urbana: más allá de la consulta ciudadana. En S. d. Distrital, De la Renovación a la Revitalización. Desafios para Bogotá. (págs. 180-197). Bogotá: Bogotá Humana.

Pérez , A. L. (2014). El hábitat residencial según sus transformaciones: soluciones del Instituto de Crédito Territorial en Bogotá. Bitácora, 61-76. 


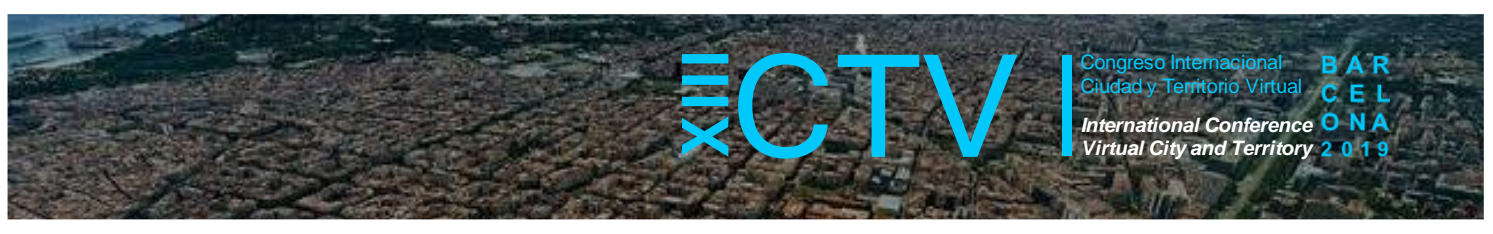

Pérez, F. (2015). La renovación urbana en contexto. En Secretaría Distrital de Planeación Bogotá, De la renovación a la revitalización: desafíos para Bogotá (págs. 20-34). Bogotá: Bogotá Humana.

Pinilla, J. F. (2016). Land Readjustment as a Means of Participation and Inclusion of Communities in Urban Renewal: The Experience of the Fenicia Project in Bogotá. Bogotá.

Universdiad de Los Andes. (2014). Ajustes a la formulación Plan Parcial Triángulo de Fenicia. Bogotá.

Universidad de Los Andes. (2012). DTS Plan Parcial Triángulo de Fenicia. Bogotá.

Vivienda, M. d. (15 de Mayo de 2017). Ministerio de Vivienda. Obtenido de Subministerio de la vivienda. Recuperado de http://www.minvivienda.gov.co/viceministerios/viceministerio-devivienda/espacio-urbano-y-territorial/macroproyectos-de-inter\%C3\%A9s-social-nacional 